\title{
Bridging the Perspectives and Developmental Needs of All Participants in Curriculum-Based Telementoring Programs
}

D. Kevin O'Neill

Simon Fraser University

Judi Harris

College of William \& Mary

Follow this and additional works at: https://scholarworks.wm.edu/educationpubs

Part of the Education Commons

\section{Recommended Citation}

O'Neill, D. K. \& Harris, J. B. (2004-2005). Bridging the perspectives and developmental needs of participants in curriculum-based telementoring programs. Journal of Research on Technology in Education, 37(2), 111-128.

This Article is brought to you for free and open access by the School of Education at W\&M ScholarWorks. It has been accepted for inclusion in School of Education Articles by an authorized administrator of W\&M ScholarWorks. For more information, please contact scholarworks@wm.edu. 


\title{
Bridging the Perspectives and D evelopmental Needs of All Participants in Curriculum-Based Telementoring Programs
}

\author{
D. Kevin 0 'N eill \\ Simon Fraser University \\ Judith B. H arris \\ College of William \& M ary
}

\begin{abstract}
Telementoring, also referred to as e-mentoring or online mentoring, has been carried out in a widerange of $\mathrm{K}-12$ environments and continuesto grow in popularity. Through a review of several studies, we argue that the potential for telementoring to support deeper and more authentic school learning will not be fully realized unless researchers pay more conscious attention to the devel opmental character of telementoring relationships. We discuss theflaws of up-front training as an approach to improving program outcomes, and compare three other strategies (iteration, facilitation, and open access to models) that can be used in combination to supplement training. (Keywords: Telementoring, mentoring, relationships, development, training, program management.)
\end{abstract}

People can play a role in social processes with someone else only to the extent that they comprehend the other's frames of reference, meaning and talk. It is that extent of comprehension that effectively determines (in the sense of limits) the boundaries of the relationship they each have with the other. (Duck, 1994, p. 54)

\section{INTRODUCTION}

Knowledgeable adults working and learning outside school systems have a lot to contribute to the education of our children. For many years, teachers have invited parents and volunteers into their classrooms for events such as science fair judging or "career day." But during such occasional visits, even very knowledgeable adults cannot significantly influence the topics that students can study deeply, or the understandings they can construct of them. As Dewey (1966) noted more than a hundred years ago, teaching often obscures the connection between school subjects and life. For the most part, brief visits from experts reinforce traditional pedagogies that, as Scardamalia and Bereiter (1997) have noted, sacrifice depth of understanding for breadth of coverage, and revolve around tasks rather than ideas.

The Internet makes possible much deeper and more routine connections between schools and adult work environments in which learning has high priority. In recent years, telementoring (also called "e-mentoring" or "online mentoring") program directors have achieved considerable success in their efforts to engage 
$\mathrm{K}-12$ students and knowledgeable adult volunteers worldwide in long-term, curriculum-based relationships (Bennett, Hupert, Tsikalas, Meade, \& Honey, 1998; Cravens, 2003; Ferneding-Lenert \& Harris, 1994; Fulop, 2002; Harris, 2003; Lewis, 2002; O’Neill, in press; O'Neill, Wagner, \& Gomez, 1996). The common purpose of these efforts, and of the volunteers involved in them, has been to enable teachers and students to pursue more ambitious schoolwork than would be feasible without external assistance. Because many adults find it inconvenient to share their expertise by visiting schools, telementoring may be a practical way to give students and teachers expanded opportunities to engage as legitimate peripheral participants (Lave \& Wenger, 1991) in communities of practice beyond the confines of the school.

Recently, researchers have focused greater attention on understanding what will be necessary to bring telementoring programs to scale (Cravens, 2003; Fulop, 2002; O'Neill, Weiler, \& Sha, in press). We argue here that future efforts will be limited in important ways by our understanding of the expectations that participants (including students, mentors, and classroom teachers) bring to their work online. How these expectations lead participants to interpret and respond to the experiences they have together can and should shape the design of telementoring programs in the future. Below, we look back over several years of research and argue that to realize the large potential of telementoring, the designers of telementoring programs must examine their work through the lens of human development.

\section{A NEW MODE OF VOLUNTARISM FOR EDUCATION}

To appreciate what telementoring is and how it works, it is important to understand how it differs from ways in which knowledgeable volunteers have more commonly been involved in education.

\section{Ask-an-expert}

One traditional way for adults to become involved in education is through question-and-answer sessions. For example, representatives from a local company might visit a school to talk about careers in their industry. Although this can be quite meaningful in the right circumstances, it is not practical for many adults to visit schools this way. Thus, a number of organizations have developed online services that allow students and teachers to get factual questions answered by a knowledgeable adult, much in the way they would during an inperson visit. Many such "Ask-a" services exist (The Virtual Reference Desk, 2003), such as "Ask Dr. Math" (The Math Forum at Drexel, 2003), or "Ask an American History Question" (U.S. National Park Service, 2003).

An important limitation of "Ask-a" services is that they do not give students the opportunity to develop ideas with the same adult over time. The question that a student submits today and the question he or she submits tomorrow may go to two different people; thus, the possibility of students developing a complex idea under the guidance of a single knowledgeable adult is precluded by design. The satisfaction the adult can gain from watching students' ideas develop is similarly curtailed. 


\section{Tutoring}

Tutoring is often confused with mentoring because it involves an ongoing relationship between a student and a more knowledgeable person, but there are important differences. One is the source of the problems that the student and the expert work on together. In tutoring, the objective is that the student master a well-defined domain (e.g., high school geometry). The expert assigns the student a problem (say, a proof), and the student solves it under the tutor's watchful eye. The tutor then evaluates the student's performance, may provide some further instruction, and assigns a new task. Throughout, the tutor is typically in control of which problems the student addresses. Mentoring is quite different in that mentoring interactions usually revolve around problems that the junior party brings to the table.

In education, formal mentoring programs have been created to (a) advise and support teachers in the early years of their careers (e.g., Little, 1990); (b) support the development of students in traditionally disadvantaged groups (e.g., Tomlin, 1994); (c) bring adult professionals to classrooms on a regular basis (e.g., EDC, 1994); or (d) bring students into laboratories or other adult workplaces periodically (e.g., Waltner, 1992). Unfortunately, many worthwhile mentoring programs have not become widespread enough to have had much influence on how students are educated in core subjects such as science and social studies.

\section{Curriculum-Based Telementoring}

In telementoring, we take the opportunity to loosen the time and space constraints that hamper formal mentoring programs by drawing upon mentors living in places that may be remote from the mentees (Hamilton \& Scandura, 2003). Rather than physical proximity and personal schedules being criteria for assigning mentors, expertise is allowed to take precedence. In $\mathrm{K}-12$ settings, appropriately selected telementors can make it more practical for teachers and students to pursue a wide variety of curriculum-related interests. For example, in one well-documented high school science classroom, student teams researched such divergent topics as earthquakes, black holes, and the swimming motions of the plesiosaur under the guidance of different volunteer scientists (Polman, 2000).

An important part of what a telementor does is to facilitate students' best thinking by "problematizing" their work. As most teachers know, inexperienced investigators often bite off more than they can chew, or trim a problem down to trivial proportions. The involvement of telementors as a critical audience can reduce the likelihood of this, while improving the quality of students' thinking. In a study of telementoring in the high school science classroom mentioned above, it was found that students' effort to sustain their mentoring relationships correlated significantly with their use of sophisticated argument strategies in their final reports. Students who sustained their relationships were likely to anticipate possible objections to their work. Neither students' argument strategies nor their effort to sustain their mentoring relationships were predicted by grades on a traditional content-based test (O'Neill, 2001). 


\section{A Telementoring Relationship ${ }^{1}$}

Closer examination of one telementoring relationship may help clarify the benefits we have been describing, and reveal some of the challenges that come with them. In an ongoing design experiment called "Tracking Canada’s Past" (O'Neill et al., 2003), O'Neill's team has been working to build a distributed community of historical inquiry. During 10 weeks each year, students in different cities work alongside their peers to deeply understand a multi-faceted historical theme-the building of the Canadian Pacific Railway in the late 1800s. In this work, students use historical evidence available in their hometowns, as well as online and in the library. Throughout, they are supported by practitioners of history (graduate students, museum staff, and preservationists) who serve as telementors.

This example involves a group of $10^{\text {th }}$ grade Social Studies students in British Columbia and a History MA student named Sandra ${ }^{2}$, who mentored them from Ontario. The relationship between Sandra and her mentees illustrates the role that a telementor can play in helping students progress from a simple acceptance of school knowledge to a more sophisticated understanding of its basis.

Sandra's mentees, Dave, William, Yen, and Kimi, were adept at Web use and chat services, but they had never participated in an asynchronous relationship like this one before. Sandra was a first-time telementor, but brought to her work a depth of knowledge about the Canadian Pacific Railway, as her thesis research included material relating to this theme.

One of Sandra's early messages shows how she gradually revealed the complexity of the history the students were studying. In it, she refers to two standard first-year university Canadian History texts that attempt both grand narrative and specific detail. They are cross-referenced with other texts, as well as with Web sites, and include historiography sections where conflicting versions of a story are examined - something not often done in K-12 history teaching, but important to understanding how historical knowledge is made (Barton, 1997). Sandra's notes also modeled the types of questions historians ask, as demonstrated in her relationship with student Kimi. Kimi developed a particular interest in how the railway influenced the native peoples of western Canada, to whose traditional lands it brought large numbers of European settlers for the first time. She described her interests vaguely at first, but responded well to Sandra's prompts to define her terms and frame of reference -essential steps for a historical inquiry:

Sandra: ... When you say "natives and communication" do you specifically mean the [Canadian Pacific] telegraph, or are you thinking of other [means] of communication as well?

...Do you want to answer both (natives communicating with native systems, and natives communicating with European/Canadian systems, or just one of the two?

${ }^{1}$ This case study borrows from work by Anne Martin and Marion Lort, both graduate students at Simon Fraser University.

${ }_{2}^{2}$ All names are pseudonyms. 
...Give this a think, then, if you want write back, and let me know which communications systems you mean specifically, because the more specific you can be, the easier it is. Do you mean just the telegraph? Do you want to include the mail? Which dates are you looking at (i.e. between 18?? And 18??).

Later, Kimi developed an interest in one of the more hotly debated figures of early $\mathrm{Ca}$ nadian history: Louis Riel. Of Metis (mixed French and aboriginal) descent, Riel mounted a rebellion against the Canadian government in 1870, and established a shortlived republic. His later arrest and hanging for treason continue to be questioned by historians (Newman, 1999). Anticipating what Kimi will discover in further reading, Sandra introduces the idea of intellectual dialogue between historians, suggesting that there is usually room for debate and reexamination of events. In her response, Kimi appears to be drawing closer to an understanding of history as no more (and no less) than a reconstruction of past events:

Kimi: I think Riel is a hero, how can he be a traitor? He was born to be a Metis, of course he should protect the Metis rights. ... what I should write for this project, rewrite the History?

The opening paragraph of Kimi's final paper contains a quote from a western Canadian historian that "The Canadian Pacific Railway linked the hearts of all Canadians." Kimi uses this quotation to identify the majority viewpoint, then goes on to challenge it:

However, is this the real picture of what the CPR brought to ALL Canadians? What about the First Nations?... Did the CPR link their hearts also? ... Their hearts were torn into pieces as Donald Smith drove the last spike of the CPR.

Clearly, Sandra's role in Kimi's research was not simply that of an answer-provider. In the questions she asked and the advice she offered, she helped Kimi to progressively reframe her research as she came to understand more about both the events she was studying and the nature of historical knowledge. However, while mentors like Sandra provide advice, it is up to the students to use it. In this way, telementoring has a natural affinity with teaching that seeks to cultivate greater epistemic agency (e.g. Scardamalia and Bereiter, 1991) and selfmanagement of learning (Nesbit \& Winne, 2003).

\section{TELEMENTORING AS A VENUE FOR HUMAN DEVELOPMENT}

The previous example illustrates an important general point about curriculum-based telementoring relationships. Although they draw inspiration from traditional mentoring relationships and can attempt to emulate them in many ways, they develop differently and serve different needs. There are several reasons for this, some of which we believe have to do with the nature of the media used, and others of which have to do with the organizational and developmental distances that telementoring relationships span. 
Currently, most telementoring occurs using e-mail—an asynchronous (timedelayed) and primarily text-based medium. Because e-mail lacks the full spectrum of visual and auditory cues that people depend upon (often unconsciously) in face-to-face conversation (Sproul \& Kiesler, 1991), e-mail mentoring requires different interaction strategies than face-to-face mentoring to create maximal educational benefit. For example, more frequent and more explicit purpose-setting, progress-reporting, and problem-solving communications may be necessary online than face-to-face (Kimball \& Eunice, 1999).

Other differences between curriculum-based telementoring and traditional faceto-face mentoring have little to do with the particular communication tools that students and mentors use. Rather, they stem from the developmental and organizational distances between telementors and their mentees. Duck (1994, p. 57) has described human relationships as "unfinished business," to emphasize the powerful ways in which interactions within relationships are influenced by the expectation of further interactions in the future. This description provides an important insight into the differences between mentoring relationships in online and face-to-face contexts. They are about business of different kinds.

Workplace mentoring relationships are largely meant to facilitate the mentees' transit through the organizational context that surrounds them and their mentors (Kram, 1985). In contrast, the $\mathrm{K}-12$ telementoring relationships that we discuss here take place between people (students and adults) who work and learn in different settings. This has large implications. Though all of the mentors who participate in our work were once students themselves, they and their mentees sometimes struggle to understand their new learning partners' perspectives, and how they can best coordinate their thoughts and actions in light of them. For example, because most telementors have easy access to telecomputing tools throughout the work day, they are accustomed to having rapid, multiple-turn exchanges with distant colleagues. As K-12 students and teachers typically have much less convenient access to telecommunications facilities, they sometimes frustrate mentors' expectations of quick turnaround.

However, mentors and mentees not sharing a workplace can also be advantageous. One traditional concern with workplace mentoring relationships is that the mentor (who is usually a more senior person) might take advantage of his or her lower-status mentees (Kram, 1985). A mentee may, for example, feel compelled to take on work he or she should not, in the hope of building goodwill with a mentor. Even if there is no abuse, concern about the appearance of impropriety can complicate or stifle the development of mentoring relationships. In curriculum-based telementoring relationships, this potential complication is eliminated. Mentees may also feel freer to voice questions and concerns that they don't want the reputation of having asked. In WINGS Online, a program for new $\mathrm{K}-12$ teachers, mentoring by master teachers from other schools or districts was reported to have this benefit (Abbott, 2003).

Thus, building and maintaining telementoring relationships can be a new and challenging task for students and adult volunteers, even if they have experience with face-toface mentoring and telecommunications (e-mail, instant messaging, etc.). In keeping with the developmental nature of mentoring relationships, students and their mentors must build understandings of their new roles. In the following sections, we discuss several studies of this process and how it can be supported. 


\section{GROWING INTO THE ROLES OF TELEMENTORING}

In telementoring as in other forms of social engagement, people need to learn the roles appropriate to the scene in order to play their parts (Schank \& Abelson, 1977). As Harris and her collaborators have explained, this is more challenging than one might suspect in the context of telementoring (Harris, O’Bryan, \& Rotenberg, 1996). Above, we discussed the challenges that organizational distance between mentors and mentees can present. Another challenge stems from the fact that mentors and mentees begin developing their understandings of telementoring from different sets of expectations.

In design experiments conducted in two Toronto-area high schools between 1997 and 1999, O'Neill investigated how high school students' and adults' conceptions of the mentor role differed, even after careful orientation. Five-week telementoring relationships were orchestrated for 112 students in grades 9 and 11 who were enrolled in general science and biology courses. These students worked with knowledgeable adult volunteers as part of a 10-week "independent study unit" in which students traditionally write library research essays.

At the end of the unit, both the students and their mentors completed a brief survey that asked them to reflect on their telementoring relationships in several ways. One item on the survey was designed to examine participants' desires to give and receive particular kinds of advice and guidance. In the students' version of the survey, respondents were asked to rate the importance of 10 different mentoring "functions" (types of advice, guidance, or help) that a mentor could have performed for them in the course of their relationship. These Likerttype ratings were solicited with a question that asked, "What would your mentor ideally have done?"

The 10 mentoring functions listed were:

- Helped me come up with a question/idea to investigate

- Asked me questions to help me think about my research

- Answered questions I had about scientific ideas

- Gave me background information on my topic

- Gave me locations on the Internet where I could find resources to answer my question

- Helped me to understand material I was reading about my topic

- Suggested challenging things for me to do that would improve my project

- Reviewed my work as I went along and helped me keep on track

- Suggested specific strategies that would help me get my work done

- Suggested books/magazines/scientific journals that I should read.

A similar set of prompts was used in surveys administered to 24 volunteer telementors. In this version of the survey, the 10 mentoring functions were presented for rating under the following question:

The following questions are about the types of mentoring activities that you would most like to undertake in the future. For each type of 
advice, guidance or assistance listed below, choose a number between 1 and 5 to indicate how much you would enjoy offering it to students. ( $1=$ not at all, $5=$ very much)

A factor analysis was performed on students' ratings of the 10 functions, to examine whether they might have been shaped by some smaller number of underlying factors. As detailed in Table 1, four of the 10 functions loaded on Factor 1: background information, pointers to Internet resources, references to reading materials, and ideas about viable project topics or questions. Because each of these functions corresponds to a serious challenge that students face in the beginning phases of an open-ended inquiry (Polman, 2000), this factor was labeled "inquiry jumpstart."

\section{Table 1: Factors underlying students' ratings of the desirability of 10 telementoring functions.}

\section{Factor 1 (Inquiry Jumpstart)}

Pointers to Internet resources

Background information

Readings

Help shape project idea/question .61

\section{Factor 2 (Inquiry Partner)}

$\begin{array}{lll}.83 & \text { Offer challenges } & .81 \\ .73 & \text { Ask questions } & .78 \\ .68 & \text { Review work } & .73 \\ .61 & \text { Help interpret data and learning } & \\ & \quad \text { resources } & .67 \\ & \text { Suggest strategies } & .54 \\ & \text { Explain scientific ideas } & .52\end{array}$

Collectively, the jumpstart functions do not imply an ongoing relationship between students and their mentors. For example, one can easily conceive mentees taking the information resources offered by mentors and continuing their work independently. However, the functions loading on Factor 2 do seem to imply a continuing partnership. By asking questions, reviewing students' work, and offering ideas about challenging things that students can do to learn more, a mentor can set up opportunities to remain involved in students' learning. As a set, the inquiry partner functions are more clearly consistent with the reciprocal nature of the classic mentoring relationship (Kram, 1985).

Ideally, mentors' and mentees' desires to give and receive the jumpstart and partner functions would be complementary, but despite careful orientation, this wasn't the case in O'Neill's study. On the basis of the factor analysis described above, two "role scales" were constructed to reflect a student's or mentor's desire for "inquiry jumpstart" or "inquiry partner" functions. An individual's score on each scale was the sum of the respondent's ratings for the functions loading on the corresponding factor, normalized to a scale from 1 to 10 .

Encouragingly, students' desires for inquiry jumpstart functions did not differ significantly from mentors' desires to provide them. In this respect, the mentors' and students' conceptions of "good" telementoring seemed well coordinated. On the other hand, a Mann-Whitney U test indicated that mentors' desires to provide the inquiry partner functions were significantly higher than the stu- 
dents' desires to receive them $(\mathrm{p}<.01)$. The difference between the means was one full point on the 10-point scale.

Students' and mentors' differential ratings of the inquiry partner functions points toward a gap to be bridged between students' and mentors' conceptions of "good" curriculum-based telementoring. This gap may reflect a number of influences, including both developmental differences between mentors and mentees, and a self-selection effect based on the recruiters' descriptions of the mentor role. In any case, the gap is of concern for the reason suggested by the quotation we used to open this article. To the extent that mentors and students diverge in their ideas about what telementors can and should do, it will be difficult for them to coordinate joint thought and action.

\section{Supporting mentors and mentees growth: Why training may fall short}

As we mentioned above, telementors and their mentees usually receive formal preparation to play their roles. However, although there is good evidence to suggest that up-front training can make a difference in program outcomes (Kasprisin, Single, Single, \& Muller, 2003), evidence also points to limitations in what can be achieved in this way. These limitations are illustrated in a study recently completed in conjunction with Tracking Canada's Past, which aimed to answer two questions:

- What are students' a priori expectations of telementoring?

- What are the strongest influences on their judgments of the success of their telementoring relationships?

Seventy-two $10^{\text {th }}$ grade students participated in the study (Asgari \& O'Neill, 2004). As part of the data collection, students were asked to rate a set of 13 widely varying telementoring functions in three different ways. The functions were variants on the 10 functions listed above. Prior to being assigned mentors, students rated each function according to the degree to which they thought a mentor might perform it for them. At the completion of the 10-week curriculum unit, during which students worked with assigned mentors, they rated each of the same 13 functions according to both the degree to which they recognized their mentors as having performed it for them, and the degree to which they felt their mentors would have performed it in the "ideal" mentoring relationship. Each student was also asked to rate the overall success of his or her telementoring relationship.

What emerged from the data analysis was striking in two ways. First, the functions most highly rated by students on the pre-survey bore little relationship to those that determined their ultimate judgments of success in the telementoring they experienced. In the pre-survey, for example, $83 \%$ of students expressed a strong expectation that their mentors would "help me understand material I read about my topic." Only $45 \%$ expressed a strong expectation that their mentors would "ask me questions to help me think about my research." However, multiple regression analysis showed that the biggest single predictor of students' judgments of the overall success of their mentoring relationships was the degree to which their mentors asked helpful questions (ac- 
cording to their report). In fact, this one variable accounted for $44.6 \%$ of the variance in students' judgments of success. A second striking finding was that students' desires for a number of the functions changed significantly from the beginning of the project to the end, despite up-front training.

Mentor and mentee training can certainly be improved; but probably not so much that mentors' and mentees' expectations would be perfectly aligned, given the developmental distances and self-selection effects at work. Therefore, we choose to support our program participants' growth into the roles and norms of telementoring through other means as well. Below we discuss three strategies that we have used: iterative cycles of telementoring, direct facilitation, and open access to models.

\section{Iterative cycles of telementoring}

The simplest way to help both students and mentors grow into their roles is to give them practice in them. This approach was taken by O'Neill and Wagner in their work with the CoVis project (O’Neill et al., 1996). In Wagner's classroom, students carried out three lengthy science projects over the course of one school year, usually under the guidance of a different volunteer telementor each time. Although this design was intended mostly to help students refine their skill in carrying out empirical investigations (by trying, stumbling, and trying again), it also gave students and mentors opportunities to try out their respective roles, make mistakes, and apply the lessons learned to new relationships. This type of "failure-driven learning" has been defended strenuously on theoretical grounds (Schank, 1982).

There are important limitations to this strategy, however. In many settings, teachers may not be able to invest classroom time in several telementored curriculum units. Like Wagner, they would have to believe in the value of iteration for achieving other, more focal curriculum goals. Relying exclusively upon trial-and-error learning may also result in a large number of "failed" relationships, which could lead to substantial attrition of volunteers. Both of these complications work against the sustainability of telementoring efforts.

\section{D irect facilitation}

For more than a decade, Harris and her collaborators in the Electronic Emissary Project have supported students' and mentors' growth into their roles through an approach they call "direct facilitation." In this approach, mediumspecific strategies for developing and sustaining online mentoring relationships are suggested interactively by a third party, who closely follows and participates, as necessary, in the telementoring dialogue. Harris and her collaborators have found that the people best equipped to play the facilitator role are those who have experience in both Internet-based communication and $\mathrm{K}-12$ teaching. This combination of experience enables them to help project participants build mutually accessible bridges between their differing workplaces' ways (Harris et al., 1997). Facilitators "act as 'playground monitors' or gentle guides, while participants 'play in the sandbox,' developing the norms and rules [of telementoring] as they go" (Palloff \& Pratt, 1999, p. 20).

Though the nature of the facilitators' responsibilities is dependent largely upon the ways in which particular telementoring projects are structured, facilitators help members of telementoring teams to: 
- Set up and test communications facilities (e-mail lists, Web fora, etc.)

- Introduce themselves, getting to know each other personally and professionally

- Set realistic project goals and expectations

- Get answers to procedural questions

- Adjust goals and expectations according to project developments

- Keep communication flowing throughout the project period

- Identify, address, and resolve miscommunications

- Structure and participate in different kinds of online activities

- Evaluate individual and group contributions to learning/teaching.

Facilitators must be careful to assist and suggest, rather than direct. This is more easily said than done, especially in the case of an electronic team that is not communicating regularly or effectively. It is essential that team members assume responsibility for the success of the exchange. As one seasoned facilitator explained to some less experienced peers,

You have now set the stage for the exchanges to begin and, at this point, it is up to the participants to "take charge." Let them know that you are available to answer any questions that they have and will be happy to assist them in any way you can, then take a step back and see what happens. (Wadbrook, 1999)

In many cases, this means that the facilitator must "translate" for and advise telementoring team participants, using only her accumulated experience with communicating online, and her knowledge of the differences between $\mathrm{K}-12$ schools and other contexts. For example, Figg (1997) analyzed a series of misunderstandings among a telementor, teacher, and students with whom she agreed to work:

As she communicates with the students regarding health issues, [the mentor] constantly points out that many issues in health require a medical doctor. The teachers and lab teachers have "interpreted" this personality as not making an effort to communicate with the students and are disgruntled with the progress of the project, which is not how I interpret her online personality at all. ...I have spent much time communicating with [the mentor] to get her to personalize her responses more and open up more with the students.... And, I have spent much time talking with the classroom teacher regarding how she could help the students form better questions for [the mentor]. In addition, I have spent time with the students suggesting ways to improve their questioning techniques. (Figg, 1997)

This facilitator's description illustrates the sensitive work that able facilitators can do to overcome misunderstandings between mentors and mentees, as they grow into their roles. It may be necessary to provide direct facilitation in networked learning environments at this early time in the history of $\mathrm{K}-12$ 
telementoring experiences, because by one estimate, without active facilitation only about $30 \%$ of all projects attempted reach fruition (Kerns, 2000). However, the ultimate goal of every facilitator should be to eliminate the need for her functions (Wadbrook, 1999).

As with the iteration strategy, facilitation has limitations. The most important of these is cost. Because able facilitators bring both technological and pedagogical skills to their work, and because they must be very reliable, they normally command a salary. This cost alone can significantly limit the capacity of a program to reach large numbers of students. And where cost is not an obstacle, the supply of qualified facilitators may be. Because she works in a college of education, Harris has been able to locate able facilitators with relative ease. Other types of host organizations might find this to be a greater challenge.

\section{0 pen access to models}

A third strategy, open access to models, appears to be less time-intensive than iteration and less resource-intensive than direct facilitation. As part of research mentioned earlier (O'Neill, in press), telementoring relationships were orchestrated for 112 high school students in a shared electronic workspace called Knowledge Forum (Learning in Motion Inc., 1997). This arrangement allowed students and their mentors to observe and learn from not only their own telementoring relationships, but also one another's experiences when they felt motivated to do so. Because these telementoring dialogues involved circumstances and personalities that were familiar to students, lessons drawn from successful relationships might be transferred more easily than they would be from "canned" cases involving unfamiliar people and circumstances.

The arrangement worked as follows: After declaring their research interests, students were organized into thematic "working groups" of varying sizes, from a single student to 10 or more. As in other telementoring programs, "matches" were then made between each of these working groups and a volunteer mentor with related expertise, who oversaw their research. Within the public Knowledge Forum workspace that mentors and students shared, "views" (analogous to conferences) were set up to help the various research groups organize their efforts. However, while each student and mentor had a "home" view in which to place their research notes and communicate, these were open to all participants.

In this setting, students spontaneously used the affordances of the Knowledge Forum software and the telementoring participation structure to seek models for their own behavior - despite not having been told to or awarded grades for doing so. This "open model-seeking" allowed students to emulate the best practices they observed among their peers and peers' mentors. As one student explained in an interview:

Yeah that's what I found [Knowledge Forum] really useful for...not just in my [part of the database], but when I looked around...it was nice to see where people were, so I knew if I was ahead or if I was, like, behind a little bit. So...it was nice to see...what other people were doing. 
Students didn't merely enjoy the freedom to observe their peers' mentoring relationships, however. Analysis of data from student surveys and records of their reading behavior in the database suggested that those who observed the mentor relationships of their classmates became "choosier" about what they wanted from telementoring. In particular, reading in the database correlated significantly with desire for the kinds of advice and guidance associated with an inquiry partner, as opposed to a jumpstart (O’Neill, in press).

Like iteration and facilitation, the model-seeking strategy has costs. One of these may be social friction. In classrooms in which private e-mail telementoring takes place, students occasionally swap stories about whose mentors have offered the most generous support, but direct comparisons between mentors are difficult. Public telementoring, in contrast, affords not only the constructive model-seeking behavior described above, but less constructive comparisons of mentor performance. Students on the "losing" end of such comparisons may become bitter if their attention is not drawn to the effort mentees must invest to make their mentors' contributions possible.

\section{Whither strategies for growth?}

Iteration, facilitation, and open model-seeking are not mutually exclusive strategies. Under the right conditions, all three could be combined. Above, we offered a sketch of the benefits and costs associated with each strategy, but ultimately what is needed to support the design of more effective telementoring programs is a cost/ benefit analysis of combinations of these strategies and their benefits for each of the major role groups involved (students, mentors, and teachers). There is clear potential for quasi-experimental research into these issues.

\section{FULFILLING THE DEVELOPMENTAL NEED S OF TELEMENTORS AT SCALE}

We believe that telementoring could play a useful role in strengthening curriculum reform efforts throughout the United States and Canada, but only if the organizers of telementoring programs dedicate themselves as thoroughly to serving the developmental needs of their volunteer mentors as their student participants. Most of our readers will appreciate how important a sufficient number of qualified volunteers is for a successful implementation of telementoring, but they may not be aware of the prevalence of voluntarism in our society, or the developmental needs that drive it.

In 1987, survey-based studies of volunteering were conducted in both the United States and Canada using sample sizes of 60,000 and 70,000 people respectively (Hayghe, 1991; Ross \& Schillington, 1988). Altogether, the volunteer labor force amounted to roughly 43.3 million people, most of whom contributed between 3 and 5 hours per week-considerably more than the commitment required of telementors in the work discussed here. Statistics Canada reproduced previous findings that the likelihood a person will volunteer increases with both level of education and household income (Hall et al., 1998). When one considers recent figures for educational attainment, voluntarism, and home Internet access, the potential number of volunteer telementors seems quite large (see Table 2). 


\section{Table 2: Likely limits of willing and qualified telementors}

\begin{tabular}{llccl} 
Country & $\begin{array}{l}\text { Number of } \\
\text { people with } \\
\text { bachelors' } \\
\text { degrees* }\end{array}$ & $\begin{array}{l}\text { Percentage of } \\
\text { graduates giving } \\
\text { time to teaching } \\
\text { or coaching }\end{array}$ & $\begin{array}{l}\text { Percentage of } \\
\text { graduates with } \\
\text { Internet access } \\
\text { at home*** }\end{array}$ & $\begin{array}{l}\text { Likely limit } \\
\text { of willing/ } \\
\text { qualified } \\
\text { telementors }\end{array}$ \\
\hline Canada & $3,000,695$ & 27 & 46.7 & 378,357 \\
U.S. & $30,090,000$ & 17 & 46.6 & $2,383,729$ \\
\hline Totals & $33,090,695$ & & & $2,762,086$
\end{tabular}

*: Figures from D ay and Curry, 1998 and Statistics C anada, 2000.

**: From Hayghe, 1991 and $\mathrm{H}$ all, M. et al., 1998.

***: From D ickinson and Sciadas, 1997 and N ewburger, 1999.

If program designers are to make the most of this potential, they must ask themselves why educated adults would choose to serve as telementors. Motives for volunteering were addressed in the Statistics Canada survey. Of seven nonexclusive responses available in a multiple-choice item, the one most frequently selected was "believe in cause supported by the organization" (96\%). This was followed closely by "to use skills and experience" (78\%) and "to explore one's own strengths" (54\%). Thus, while nearly all volunteers donate their time to causes they believe in, they do not do so merely to further those causes.

The findings of the Statistics Canada report parallel those of a qualitative study conducted using a set of 13 audiotaped interviews with volunteer telementors (O’Neill, Abeygunawardena, Perris, \& Punja, 2000). Without prompting, each of these interviewees mentioned that part of their motivation to serve as telementors stemmed from a desire to support students in undertaking challenging research in their field. For these volunteers - as for volunteers more generally telementoring provided an opportunity to promote a cause they believed in. However, this motivation was not pure and simple. A smaller but substantial proportion of the interviewees (7 out of 13) also expressed satisfaction with the opportunities that telementoring had given them to realize their own competence as researchers and teachers.

\section{SUM MARY AND CONCLUSIONS}

It has become a truism that the Internet will change the way our cultural institutions work (Dyson, 1998). Not all of this change will be for the better, but we believe that curriculum-based telementoring will be. Years of experience with learners and teachers in both the U.S. and Canada have shown the potential of this innovation to support new learning experiences for a host of people whose learning needs could be better served. Among them are millions of students in K-12 classrooms who rarely have the opportunity to pursue challenging, long-term inquiry, because their teachers lack the confidence or expertise to attempt it alone. The experience of telementoring could also benefit millions of knowledgeable adults, who would like to volunteer their time to work with youth, but whose schedules cannot accommodate regular visits to schools.

Here we explored some of the synergies between the learning needs of children and adults that could be more fully realized in a computer-mediated "knowledge 
society" (Scardamalia \& Bereiter, 1996). For this to occur, however, the organizational and developmental distances between telementors and their mentees will need to be better understood, and more effectively bridged. Because the ability to play the role of a good telementor or mentee is not developed in days or weeks, telementoring programs must pursue a combination of strategies for supporting mentors' and mentees' growth into their roles over time.

This agenda is key to the development of socially sustainable telementoring programs. Even with the recent explosion in access to the Internet, the number of potential volunteer telementors is finite and exhaustible, and like undergraduate tutors (Dickinson, 1999), telementors are unlikely to continue serving in this role for a period of years for purely altruistic reasons. They have their own learning agendas, which K-12 telementoring programs should consider seriously. In this article we discussed three strategies for supporting telementors' and mentees' growth, which we believe could be fruitfully combined. These strategies provide a fertile ground for experimentation, and reflect a fundamental truth about telementoring programs: that their success is continuously dependent not only upon the cleverness of their organizers, the utility of the materials they develop, and the sophistication of the software they design, but also upon the unique strengths and assets that participants bring to and develop through them.

\section{Contributors}

Kevin O'Neill is an assistant professor of Education and Technology at Simon Fraser University. He coordinates the Master's in Education and Technology program there, and directs the Online Learning Relationships Lab (http:// www.learningrelationslab.org/). (Address: Kevin O’Neill, Faculty of Education, Simon Fraser University, 8888 University Dr., Burnaby, BC, Canada V5A 1S6; koneill@sfu.ca.)

Judi Harris holds the Pavey Family Chair in Educational Technology at the College of William \& Mary, where she directs both the Curriculum \& Educational Technology doctoral concentration and the Electronic Emissary K-12 international telementoring project (http://emissary.wm.edu/). (Address: Judi Harris, School of Education, College of William \& Mary, P.O. Box 8795, Williamsburg, VA, USA, 23187-8795; judi.harris@wm.edu.)

\section{REFERENCES}

Abbott, L. D. (2003). N ovice teacher's experiences with telementoring as learnercentered professional development. Unpublished doctoral disseration, University of Texas at Austin.

Asgari, M., \& O'Neill, D. K. (2004). What do they mean by "success"? C ontributors to percei ved success in a telementoring program for adolescents. Paper presented at the annual meeting of the American Educational Research Association, San Diego, CA.

Barton, K. C. (1997). 'I just kinda know': Elementary students' ideas about historical evidence. Theory and research in social education, 25(4), 407-430.

Bennett, D., Hupert, N., Tsikalas, K., Meade, T., \& Honey, M. (1998). Critical issuesin the design and implementation of telementoring environments (CCT Technical Report No. 09-1998b). New York: Center for Children and Technology. 
Cravens, J. (2003). Online mentoring: Programs and suggested practices as of February 2001. Journal of Technology in H uman Services, 21(1/2), 85-109.

Dewey, J. (1966). Lectures in the philosophy of education, 1899. New York: Random House, Inc.

Dickinson, M. J. (1999). Do gooders or do betters? An analysis of the motivation of student tutors. Educational Research, 41(2), 221-227.

Duck, S. (1994). Steady as (s)he goes. In D. J. Canary \& L. Stafford (Eds.), Communication and relational maintenance (pp. 45-60). New York: Academic Press, Inc.

Dyson, E. (1998). Release 2.1: A design for living in the digital age. New York: Broadway books.

EDC. (1994). Industry volunteers in the classroom: F reeing teachers ti me for professional development: Educational Development Center, Inc., Newtonville, MA.

Ferneding-Lenert, \& Harris. (1994). Redefining expertise and reallocating roles in text-based asynchronous teaching/learning environments. M achine-me diated Learning, 4(2-3), 129-148.

Figg, C. (1997). Reflections from the journal of a first-time facilitator for the Electronic Emissary project [Online document]. Available: http://www.tapr.org/ emissary/candace.html.

Fulop, M. (2002). Assessing the Potential of eM entoring: A survey of current is sues. Portland, OR: National Mentoring Center, Northwest Regional Educational Laboratory.

Hall, M., Knighton, T., Reed, P., Bussiere, P., McRae, D., \& Bowen, P. (1998). Caring Canadians, involved Canadians: Highlights from the 1997 national survey of giving, volunteering and participating (Research Report No. 71542-X1E). Ottawa: Statistics Canada.

Hamilton, B. A., \& Scandura, T. A. (2003). E-mentoring: Implications for organizational learning and development in a wired world. O rganizational D ynamics, 31(4), 388-402.

Harris, J. B. (2003). Electronic Emissary. In A. Kovalkchick \& K. Dawson (Eds.), Education and Technology: An encydopedia (Vol. 1). Santa Barbara, CA: ABC-CLIO.

Hayghe, H. V. (1991, February). Volunteers in the U.S.: Who donates the time? M onthly Labor Review, 17-23.

Kasprisin, C. A., Single, P. B., Single, R. M., \& Muller, C. B. (2003). Building a better bridge: testing e-training to improve e-mentoring programmes in higher education. M entoring \& Tutoring, 11(1), 67-78.

Kerns, T. (2000). Designing collaborative projects for the Internet [Online document]. Available: http://www.techlearning.com/db_area/archives/WCE/archives/kerns1.html.

Kimball, L., \& Eunice, A. (1999, November). Zen and the art of facilitating virtual learning communities. Paper presented at the Thinkquest Teachers' Summit, Los Angeles, CA.

Kram, K. E. (1985). M entoring at work: D evelopmental relationships in organizational life. New York: University Press of America.

Learning in Motion Inc. (1997). Knowledge Forum. Santa Cruz, CA: Learning in Motion, Inc. 
Lewis, C. W. (2002). International telementoring program report: Evaluation re sultsfrom teacher surveys. Fort Collins, CO: Research and Development Center for the Advancement of Student Learning, Colorado State University.

Little, J. W. (1990). The mentor phenomenon and the social organization of teaching. Review of Research in Education, 16, 297-351.

Nesbit, J. C., \& Winne, P. H. (2003). Self-regulated inquiry with networked resources. Canadian Journal of Learning and Technology, 29 (3), 71-91.

Newman, P. C. (1999, April 12). Rewriting history: Louis Riel as a hero. M adean's, p. 48.

O'Neill, D. K. (2001). Knowing when you've brought them in: Scientific genre knowledge and communities of practice. The Journal of the Learning Sciences, 20(3), 223-264.

O'Neill, D. K. (in press). Building social capital in a knowledge-building community: Telementoring as a catalyst. Interactive Learning Environments.

O’Neill, D. K., Abeygunawardena, H., Perris, K., \& Punja, Z. (2000). The telementor's auidebook: A field guide to supporting student inquiry online (Final report of Office of Learning Technolgies project 89116 No. 89116). Ottawa: Office of Learning Technologies, Human Resources Development Canada.

O’Neill, D. K., Wagner, R., \& Gomez, L. M. (1996, November). Online mentors: Experimenting in science class. Educational Leadership, 54, 39-42.

O'Neill, D. K., Weiler, M. J., \& Sha, L. (in press). Software support for online mentoring programs: A research-inspired design. M entoring \& Tutoring, 12(3).

O'Neill, K., Sohbat, E., Martin, A., Asgari, M., Lort, M., \& Sha, L. (2003, April). Sharing accountability through sharing our accounts: Piloting an online community for high school history learning. Paper presented at the Annual meeting of the American Educational Research Association, Chicago, IL.

Palloff, R. M., \& Pratt, K. (1999). Building learning communitiesin cyberspace: Effective strategiesfor theonlinedassoom. San Francisco, CA: Jossey-Bass Publishers.

Polman, J. L. (2000). D esigning project-based science: Connecting learners through guided inquiry. New York: Teachers College Press.

Ross, D. P., \& Schillington, E. R. (1988, November). A Profile of the Canadian volunter: A guide to the 1987 Survey of Volunter Activity in Canada. Ottawa, Canada: National Voluntary Organizations.

Scardamalia, M., \& Bereiter, C. (1991). Higher levels of agency for children in knowledge building: A challenge for the Design of new knowledge media. The Journal of the Learning Sciences, 1(1), 37-68.

Scardamalia, M., \& Bereiter, C. (1996, November). Engaging students in a knowledge society. Educational Leadership, 54, 6-10.

Scardamalia, M., \& Bereiter, C. (1997). Adaptation and Understanding: A case for new cultures of schooling. In S. Vosniadou, E. D. Corte, R. Glaser \& H.

Mandl (Eds.), International perspectives on the psychological foundations of technologybased learning environments. Mahwah, NJ: Lawrence Erlbaum Associates.

Schank, R. C. (1982). D ynamic memory: A theory of reminding and learning in computers and people. Cambridge: Cambridge University.

Schank, R. C., \& Abelson, R. P. (1977). Scripts plans goals and understanding: An inqui ry into human knowledge structures. Hillsdale, NJ: Erlbaum. 
Sproul, L., \& Kiesler, S. (1991). Connections: N ew ways of working in the networked organization. Cambridge, MA: MIT Press.

The Math Forum at Drexel. (2003). Ask D r. M ath. Retrieved Nov. 8, 2003 from http://mathforum.org/dr.math/

The Virtual Reference Desk. (2003). AskA + Locator. Retrieved Nov. 9, 2003 from http://www.vrd.org/locator/

Tomlin, V. E. (1994). A mentor program for improving the academic attainment of black adolescent males. Unpublished doctoral dissertation, University of Denver, CO.

U.S. National Park Service. (2003). Ask an American H istory Q uestion. Retrieved Nov. 9, 2003 from http://www.cr.nps.gov/history/askhist.htm

Wadbrook, C. C. (1999). A facilitating experience. [Online]. Available: http://www.tapr.org/emissary/wadbrook.html.

Waltner, J. C. (1992, March). Learning from scientists at work. Educational Leadership, 49, 48-52. 